\title{
Histologic Effects of University of Wisconsin Two-Layer Method Preservation of Rat Pancreas
}

\author{
M.C. Gioviale, G. Damiano, R. Puleio, M. Bellavia, G. Cassata, V.D. Palumbo, G. Spinelli, R. Altomare, \\ R. Barone, F. Cacciabaudo, G. Buscemi, and A.I. Lo Monte
}

\begin{abstract}
Marginal donors represent a poorly utilized source of organs for transplantation despite their availability. The key is to reduce the ischemic damage in the effort to improve organ quality. This study investigated the histologic effects after in situ perfusion of preservation with a two-layer method compared with the classic University of Wisconsin preservation in term of tissue integrity and number of viable exocrine cells in the rat pancreas both after exsanguination and at 8 weeks of cryopreservation. Pancreata harvested from 60 rats were collected using 3 methods: two-layer method following University of Wisconsin perfusion; exsanguination; and classic University of Wisconsin perfusion/storage. In addition to histologic analysis of collected pancreata, we analyzed the number of $\mathrm{CK} 19^{+}$cells and their viability using chi-square tests with values $P<.05$ considered to be significant. Rat pancreas histology showed as University of Wisconsin in situ perfusion and preservation by the two-layer method to be more effective to maintain the morphologic integrity of both exocrine and endocrine tissues. There were a larger number of $\mathrm{CK}_{1} 9^{+}$cells with good viability. Moreover, the effects of oxygenation were visible in pancreas biopsies preserved after exsanguination. In situ University of Wisconsin perfusion and preservation for 240 minutes with the two-layer method yielded greater numbers and viability of $\mathrm{CK} 19^{+}$cells even after 8 weeks of cryopreservation.
\end{abstract}

$\mathbf{E}$ FFORTS TO EXPAND THE POOL of organs available for transplantation have progressively lead to acceptance of "marginal" kidneys or "expanded criteria donors" among geriatric, hypertensive, and even proteinuric individuals. A marginal organ denotes a suboptimal situation due to reduced function albeit still useful for transplantation. To improve these adverse situations requires knowledge concerning ischemic damage inherent to the transplant process. ${ }^{1-7}$

Over the last 10 years we have been exploring techniques for pancreas harvest using in situ perfusion to reduce ischemic injury in small and middle-size animals. Employing in situ perfusion we have increased the amount and quality of purified rat pancreatic exocrine cells compared with collection after exsanguination. ${ }^{8}$ Moreover we have demonstrated that ischemic injury can be minimized by static oxygenation of tissue during cold ischemia by two-layer preservation in University of Wisconsin (UW)/perfluorocarbons solution (twolayer method). ${ }^{9,10}$ Previously collection had been optimized utilizing fluorescence cell sorting to collect purified $\beta$-cell precursors from whole human adult and children pan- creata. ${ }^{11,12}$ The objective of this investigation was to determine the histologic impact of TLM compared with classic UW preservation on pancreatic tissue recovery and as secondarily to demonstrate whether TLM perfusion increased the number of viable exocrine cells from rat pancreas after in situ perfusion and 8 weeks of cryopreservation. We sought to obtain results that could translate to studies of reprogramming, ${ }^{13,14}$ resistance, and senescence of pancreatic cells.

From the Dipartimento di Discipline Chirurgiche ed Oncologiche (M.C.G., G.D., M.B., V.D.P., G.S., R.A., F.C., G.B., A.I.L.M.), Università degli Studi di Palermo, Palermo, Italy; Istituto Zooprofilattico Sperimentale della Sicilia "A. Mirri" di Palermo (R.P., G.C.), Palermo, Italy; Dottorato di Ricerca in Biotecnologie Chirurgiche e Medicina Rigenerativa nell'Insufficienza d'Organo-Coordinatore Prof Attilio Ignazio Lo Monte (V.D.P., R.A., R.B., F.C., G.B., A.I.L.M.), Università degli Studi di Palermo, Palermo, Italy; and Consorzio Interuniversitario per i Trapianti d'Organo (G.B.), Italy.

Address reprint requests to Attilio Ignazio Lo Monte, via del Vespro, 129, 90127 Palermo, Italy. E-mail: attilioignazio.lomonte@ unipa.it

0041-1345/-see front matter http://dx.doi.org/10.1016/j.transproceed.2013.02.047 
Table 1. Donor Characteristics

\begin{tabular}{|c|c|c|c|c|}
\hline & In Situ Perfusion TLM & In Situ Perfusion UW & Exsanguination TLM & $P$ \\
\hline Pancreas (n) & 20 & 20 & 20 & Ns \\
\hline Age (mo) & $2-3$ & 2-3 & 2-3 & Ns \\
\hline Weight $(\mathrm{g})$, media \pm SEM & $133.6 \pm 0.77$ & $134.7 \pm 1.00$ & $132.3 \pm 0.65$ & Ns \\
\hline Pancreas weight $(\mathrm{g})$, mean \pm SEM & $82.15 \pm 0.65$ & $83.85 \pm 0.69$ & $83.65 \pm 0.72$ & Ns \\
\hline WIT (min), mean \pm SEM & $13.65 \pm 0.55$ & $14.70 \pm 0.68$ & $13.55 \pm 0.57$ & Ns \\
\hline eCIT (min), mean \pm SEM & $241.3 \pm 1.08$ & $243.3 \pm 0.74$ & $240.8 \pm 1.23$ & Ns \\
\hline CT $(h)$, mean \pm SEM & $1344 \pm 0.31$ & $1345 \pm 0.30$ & $1345 \pm 0.46$ & Ns \\
\hline
\end{tabular}

Data expressed as mean \pm standard error of the mean.

TLM, two-layer method (UW perfluorocarbons solution); UW, University of Wisconsin solution; WIT, warm ischemia time; eCIT, exsanguination cold ischemia time; CT, cryopreservation time; NS, not significant.

\section{METHODS}

\section{Procurement and Preservation}

Whole pancreata were collected from 60 Wistar rats: 40 after in situ perfusion with UW solution at $4^{\circ} \mathrm{C}$ (ViaSpan, Bristol-Myers Squibb Italy added with dexamethasone, insulin, and glutathione) ${ }^{15}$ and 20, after exsanguination. The operative procedure was approved by our Ethics Committee and performed in accordance with International Guidelines for Animal Experimentation. ${ }^{16}$

Animals were fasted for 24 hours before collection to reduce intestinal content. The 40 pancreata collected after in situ perfusion were divided into 2 groups: 20 were saved in a sterile bag with $50 \mathrm{~mL}$ of UW solution at $4^{\circ} \mathrm{C}$ ("bag ice storage") containing UW solution at $4^{\circ} \mathrm{C}$ for 240 minutes and 20 , in a special container for 240 minutes in a static TLM solution $(500 \mathrm{~mL} \mathrm{UW}$ plus $500 \mathrm{~mL}$ of oxygenated PFC). The TLM method described in our previous work in a porcine model was adapted for the rat. ${ }^{9}$ Oxygen was filtered through $\mathrm{PFC}$ for 1 hour before preservation and the container was cooled to $4^{\circ} \mathrm{C}$. Cold ischemic time (CIT) was defined between the end of in situ perfusion and the start of pancreas digestion. ${ }^{17-25}$ The third group of 20 pancreata collected after exsanguination was preserved for 240 minutes in static TLM solution. Warm ischemic time (WIT) was defined as the time between cessation of the heartbeat and placement of the pancreas into the preservation solution. ${ }^{26}$ Exsanguination CIT (eCIT) was defined between placement of the pancreas into the preservation solution and the start of pancreas digestion.

\section{Culture and Immunostaining}

After 240 minutes of storage, exocrine tissue of three groups was separately obtained by whole pancreatic digestion using collagenase $\mathrm{P}$ (3 mg/mL; Roche) according to Gray's method. ${ }^{27}$ The tissue pellet was underlayed on a discontinuous Ficoll gradient (Sigma Aldrich, Italy) at 1108, 1096, 1069, $1037 \mathrm{~g} / \mathrm{cm}^{3}$. After $750 \mathrm{~g}$ centrifugation at $4^{\circ} \mathrm{C}$ for 18 minutes we observed 1096/1108 and 1037/1069 layer interfaces of acinar cells and epithelial ductal cells respectively. An aliquot of acinar cells or epithelial ductal cells was cryopreserved for 8 weeks using 10\% Dimethylsulfoxide (DMSO) (Sigma Aldrich, Italy) using sequential reductions of temperature before transfer into liquid nitrogen at $-196^{\circ} \mathrm{C} \cdot{ }^{28-30}$ Fresh pellets were cultured for 2 weeks in Dulbecco's Modified Eagle Medium (DMEM) media (glucose $5.6 \mathrm{mmol} / \mathrm{L}$ ) with Bovine Serum Albumine (BSA) (10\%), L-glutamine (2 mmol/L), penicillin/streptomycin $(200 \mu \mathrm{L} / \mathrm{mL})$, and fungizone $(200 \mu \mathrm{L} / \mathrm{mL}){ }^{31}$ Thereafter suspended cells were harvested, while adherent cells were identified using immunohistochemical staining for CK-19 using rat monoclonal anti- cytokeratin antibodies (1:50)/goat, anti-rat immunoglobulin Fluorescein Isothiocyanate (FITC) (1:250; Santa Cruz Biotechnology, Calif, USA) as a ductal-cell marker and 4',6-diamidino2-phenylindole (DAPI) (1:1000). The specimens were mounted cell-side down on glass slides with a drop of Distrene 80 Plasticizer dibutyl phthalate- Xylene (DPX - Sigma Aldrich, Italy) for examination using a Zeiss light microscope. Positive cells were randomly counted on the montage of generated photographs. Cell viability was assayed using trypan blue staining for nonviable cells. Trypsinized adherent cells were placed on a hemocytometer for counting. After gradual defrosting, cryopreserved cells underwent Percoll gradient separation (Sigma Aldrich, Italy; $1063 \mathrm{gr} / \mathrm{cm}^{3}$ ) to eliminate waste products after 8 weeks, subsequently undergoing the same culture protocol.

All data were expressed as percentages or mean values \pm standard errors of the mean. The groups were compared using chi-square and Student $t$ tests with values of $P<.05$ considered
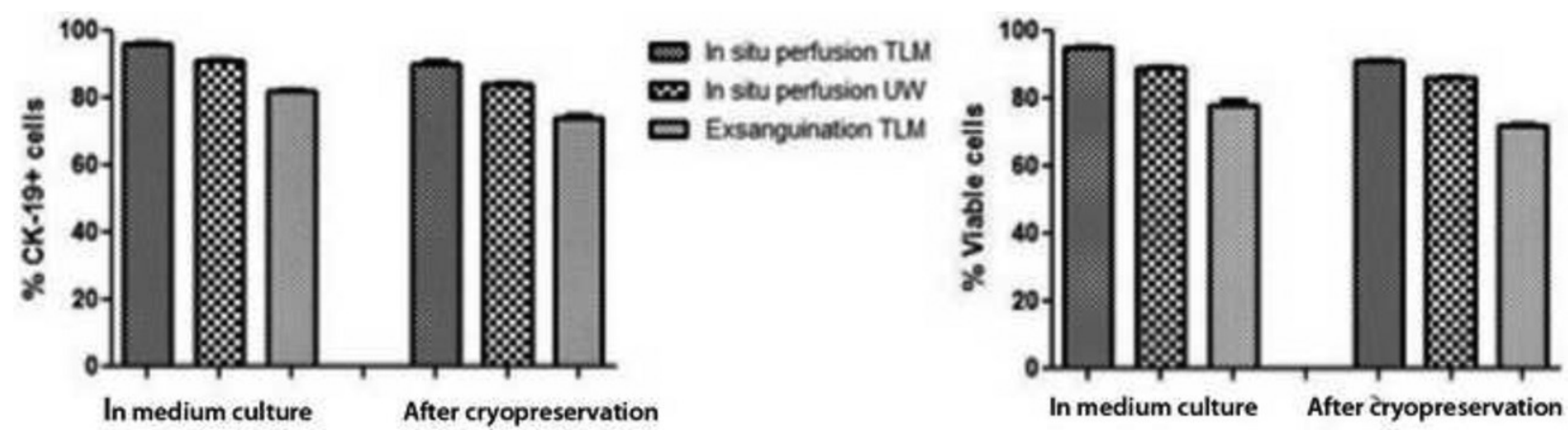

Fig 1. Percentage of $\mathrm{CK}-19^{+}$cells and viable cell induced culture medium before (left side of graphs) and after 8 weeks of cryopreservation (right side of graphs). UW, University of Wisconsin solution; TLM, two-layer method (UW/PFC solution). 
Table 2. Comparison of Ratio and Percentage of CK-19+ and Viable Cells for Both Freshly Collected and Cryopreserved Cells According to the Three Different Methods

\begin{tabular}{lcccc}
\hline & Ratio of CK-19 ${ }^{+}$Cells & \% of CK-19+ Cells & Ratio of Viable Cells & \% Viable Cells \\
\hline In situ perfusion TLM & $967 / 1006$ & 96.2 & $954 / 1002$ & 95.25 \\
In situ perfusion UW & $906 / 997$ & 91 & $884 / 995$ & 88.95 \\
Exsanguination TLM & $746 / 906$ & 82 & $625 / 800$ & 78.15
\end{tabular}

\begin{tabular}{lcccc}
\hline & After 8 Wk Cryopreservation & After 8 Wk Cryopreservation & After 8 Wk Cryopreservation & After 8 Wk Cryopreservation \\
\hline In situ perfusion TLM & $908 / 1010$ & 90 & $914 / 1010$ & 91 \\
In situ perfusion UW & $853 / 1016$ & 84 & $845 / 990$ & 85.95 \\
Exsanguination TLM & $588 / 802$ & 74.3 & $579 / 802$ & 72 \\
\hline
\end{tabular}

TLM, two-layer method; UW, University of Wisconsin Solution.
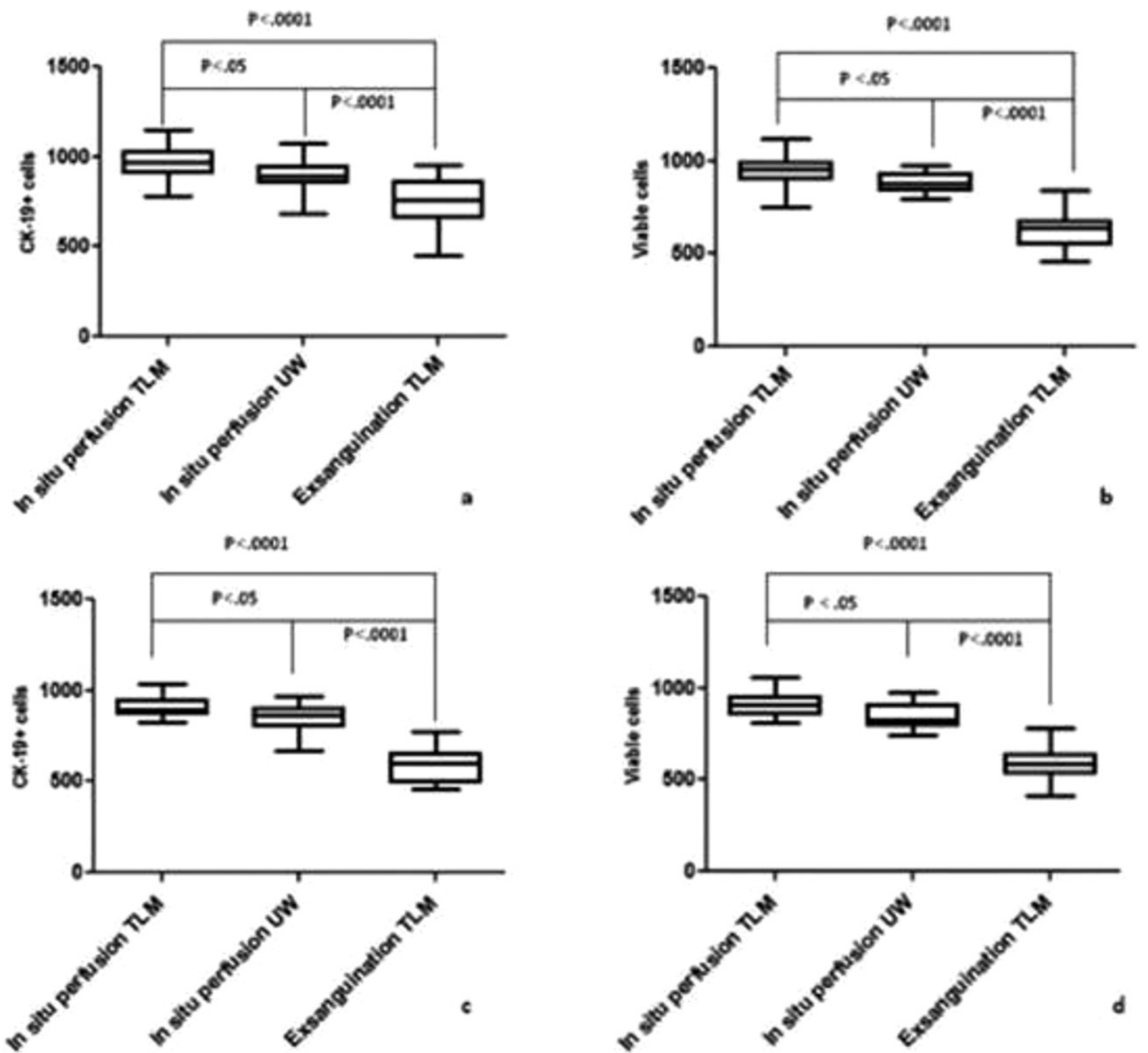

Fig 2. Whisker and box plot of CK-19+ cells and viable cells in culture medium before (a, b) and after 8 weeks of cryopreservation (c, d) in the 3 different collection methods. UW, University of Wisconsin Solution; TLM, two-layer method (UW/perfluorocarbons solution). 
significant. In situperfusion TLM freshly collected and 8-weeks cryopreserved cells were compared to In situ perfusion UW, and exsanguination group.

\section{Histology}

Pancreatic tissue samples were fixed in $10 \%$ buffered formalin for histological analysis. Biopsies randomly collected from the pancreas were embedded in paraffin, sectioned at $4 \mu \mathrm{m}$, and stained with hematoxylin and eosin.

\section{RESULTS}

Donor characteristics of the 3 groups -in situ perfusion TLM group, in situ perfusion UW group and exsanguina- tion TLM group-were similar for age, body weight, pancreas weight, WIT or CIT and eCIT, and cryopreservation time (Table 1). Fig 1 and Table 2 shows a greater number of $\mathrm{CK}_{1}{ }^{+}$cells with best viability of in situ perfusion followed by TLM preservation compared with in situ perfusion and UW solution preservation $(P<.05$; Fig 2$)$. In situ perfusion TLM showed significantly better results in term of the number and viability of $\mathrm{CK}_{1} 9^{+}$cells among collected cells $(P<.0001)$ versus exsanguination TLM or for in situ perfusion UW versus exsanguination TLM. Analysis of data on 8 weeks' cryopreserved cells revealed overlapping findings (Table 2).

Fig 3. Histologic findings. (a) Pancreas collected after exsanguination and stained with hematoxylin and eosin (H\&E; original magnification 20×): clear degeneration and diffuse vacuolization of cytoplasm with zymogen granules; nuclei with vesicular pattern due to chromatin dispersion; islets with pronounced signs of cytoplasmic vacuolization, and (b) at $40 \times$ (original magnification). (c) Pancreas collected after exsanguination, preserved in two-layer method (TLM) for 240 minutes and stained with $\mathrm{H} \& \mathrm{E}$ (original magnification $20 \times$ ): small degeneration where the apical part of exocrine cells presents eosinophil zymogen granules, with endocrine component consisting of ovoid islets whose cells have plentiful weakly eosinophil cytoplasm and nucleus put at center, (d) at $63 \times$ (original magnification). (e) Pancreas collected with in situ perfusion, preserved in TLM for 240 minutes and stained with H\&E (original magnification $20 \times$ ): initial degeneration signs represented from cell swelling, vacuolization, and nonconstant zymogen granules fusion, with nuclei increased in their volume and margination of chromatin, and (f) at $63 \times$ (original magnification). (g) Moderate interstitial edema, but good cell morphology for exocrine component, with nuclei showing regular chromatin pattern and homogeneous volume, and (h) at $63 x$ (original magnification).
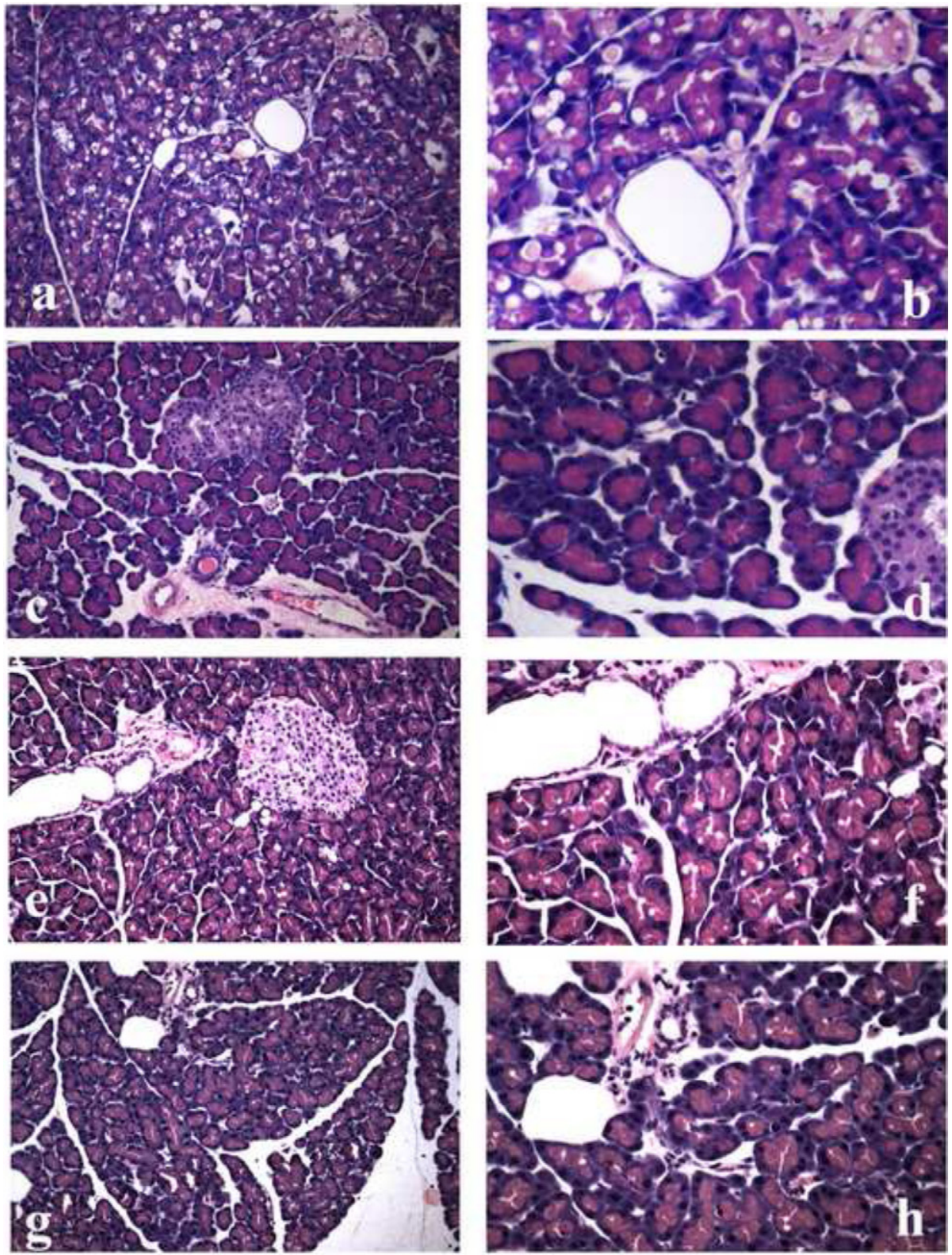
Pathologic observations (Fig 3) on biopsies from pancreata collected after in situ perfusion and preserved in TLM for 240 minutes showed little interstitial edema, but good cell morphology in the exocrine and endocrine areas. Nuclei showed a regular chromatin distribution in homogeneous volumes. There was minor degeneration among cells collected from pancreata preserved with UW, where nuclei showed a bigger volume with chromatin margination and vesicular aspects of tissue damage. Measurement of nuclear diameters of pancreatic cells preserved with UW showed a mean cell augmentation of 3 per field at higher magnification. Comparison of pancreas cells that did not undergo preservation showed nuclear diameter ranging from $5.3 \mu \mathrm{m}$ to $6.5 \mu \mathrm{m}$, and even $9.5 \mu \mathrm{m}$, whereas the nuclei with the biggest dimensions reached the $9.5 \mu \mathrm{m}$ of diameter. The initial degeneration included cell swelling, vacuolization, and in some cases zymogen granule fusion among pancreata perfused with and preserved in UW (resulted overlapping to pancreas after exsanguination and preservation in TLM). These results indicated that compared with UW solution TLM improved tissue health also TLM tissue retained serves after animal exsanguination.

\section{DISCUSSION}

In situ pancreas perfusion provokes a minor ischemic injury. Moreover, previous studies have shown that oxygenation through preservation with the TLM (UW/PFC solution) reduces cold ischemic damage even when organs are collected from non- heart-beating donors. ${ }^{10}$ Thus a combination of methods might improve pancreas preservation for short CIT, increasing cell viability and, as a consequence, extending the effective duration of preservation. This improvement might extend the donor pool to marginal organs and improve transplant outcomes. The efficacy of TLM on organ preservation is controversial. Oxygenation by perfluorocarbons has been shown to not be adequate for thick human tissues and for longer CIT. The TLM seems to be effective for small thickness tissues as the rat pancreas. ${ }^{32,33}$ Histologic analyses of rat pancreas comparing classic UW perfusion/storage with UW in situ perfusion and preservation in TLM showed that oxygenation remarkably reduced tissue necrosis maintaining good morphologic integrity of both exocrine and endocrine tissues.

The effects of oxygenation were visible also among pancreas biopsies after exsanguination. In situ UW perfusion and preservation for 240 minutes with TLM achieved better cell viability even after 8 weeks' cryopreservation. This combination could be useful where the collected cells are to be utilized for studies on cellular resistance and reprogramming of ductal to islet like-elements. ${ }^{34}$

\section{REFERENCES}

1. Baskin-Bey ES, Kremers W, Stegall MD, et al. United Network for Organ Sharing's expanded criteria donors: is stratification useful? Clin Transplant. 2005;19:406-412.

2. Goh CC, Ladouceur M, Peters L, et al. Lengthy cold ischemia time is a modifiable risk factor associated with low glomerular filtration rates in expanded criteria donor kidney transplant recipients. Transplant Proc. 2009;41(8):3290-3292.

3. Gambino G, Gioviale MC, Maione C, et al. Use of marginal donors in kidney transplantation: our experience. Transplant Proc. 2006:38(4):999-1000.

4. Xie AN, Dong NG, Zhang KL, et al. Clinical experience in the use of marginal donor hearts. Chin Med J (Engl). 2011;124(8): $1185-1188$.

5. Milan Z, Taylor C, Duncan B, et al. Statistical modeling of hemodynamic changes during orthotopic liver transplantation: predictive value for outcome and effect of marginal donors. Transplant Proc. 2011;43(5):1711-1715.

6. Muthusamy AS, Vaidya A. Expanding the donor pool in pancreas transplantation. Curr Opin Organ Transplant. 2011 Feb; 16(1):123-127.

7. Pêgo-Fernandes PM, Samano MN, Fiorelli AI, et al. Recommendations for the use of extended criteria donors in lung transplantation. Transplant Proc. 2011;43(1):216-219.

8. Damiano G, Gioviale MC, Lombardo C, et al. An old method for good new cells. Transplant Proc. 2009;41(4):1116-1168.

9. Gioviale MC, Damiano G, Cacciabaudo F, et al. A good breath of oxygen for beta-like cells obtained from porcine exocrine pancreatic tissue. Transplant Proc. 2011;43(4):1173-1177.

10. Gioviale MC, Damiano G, Palumbo VD, et al. Pancreatic islets from non-heart-beating donor pig: two-layer preservation method in an in vitro porcine model. Int J Artif Organs. 2011;34(6): $519-525$

11. Giordano C, Stassi G, Todaro M, et al. Autofluorescenceactivated sorting of human single beta cells and endocrine non-beta cells after enzymatic islet dissociation. Transplant Proc. 1994;26(2): 651-652.

12. Stassi G, Todaro M, Richiusa P, et al. Expression of apoptosisinducing CD95 (Fas/Apo-1) on human beta-cells sorted by flowcytometry and cultured in vitro. Transplant Proc. 1995;27(6):32713275.

13. Gioviale MC, Damiano G, Montalto G, et al. Isolation and colture of $\beta$-like cells from porcine Wirsung duct. Transplant Proc. 2009;41:1363-1366.

14. Bonner-Weir S, Taneja M, Weir GC, et al. In vitro cultivation of human islets from expanded ductal tissue. Proc Natl Acad Sci USA. 2000;97(14):7999-8004.

15. Belzer FO, Southard JH. Principles of solid-organ preservation by cold storage. Transplantation. 1988;45(4):673-676.

16. Demers G, Griffin G, De Vroey G, et al. Harmonization of animal care and use guidance. Science. 2006;312:700-701.

17. Kuroda Y, Kawamura T, Suzuki Y, et al. A new, simple method for cold storage of the pancreas using perfluorochemical. Transplantation. 1988;46:457.

18. Matsumoto S, Kuroda Y. Perfluorocarbon for organ preservation before transplantation. Transplantation. 2002;74(12):18041809.

19. Matsumoto S, Kuroda Y, Hamano M, et al. Direct evidence of pancreatic tissue oxygenation during preservation by the twolayer method. Transplantation. 1996;62(11):1667-1670.

20. Kuroda Y, Fujino Y, Morita A, et al. Oxygenation of the human pancreas during preservation by a two-layer (University of Wisconsin solution/perfluorochemical) cold-storage method. Transplantation. 1992;54:561-562.

21. Matsumoto S, Rigley TH, Qualley SA, et al. Efficacy of the oxygen-charged static two-layer method for short-term pancreas preservation and islet isolation from non human primate and human pancreata. Cell Transplant. 2002;11:769-777.

22. Morita A, Kuroda Y, Fujino Y, et al. Assessment of pancreas graft viability preserved by a two-layer (University of Wisconsin solution/perfluorochemical) method after significant warm ischemia. Transplantation. 1993;55:667-669.

23. Kuroda Y, Morita A, Fujino Y, et al. Successful extended preservation of ischemically damaged pancreas by the two-layer 
(University of Wisconsin solution/perfluorochemical) cold storage method. Transplantation. 1993;56(5):1087-1090.

24. Tsujimura T, Kuroda Y, Avila JG, et al. Resuscitation of the ischemically damaged human pancreas by the two-layer method prior to islet isolation. Transplant Proc. 2003;35:2461.

25. Hiraoka K, Kuroda Y, Suzuki Y, et al. Outcomes in clinical pancreas transplantation with the two-layer cold storage method versus simple storage in University of Wisconsin solution. Transplant Proc. 2002;34:2688.

26. Matsumoto S, Okitsu T, Iwanaga Y, et al. Successful islet transplantation from nonheartbeating donor pancreata using modified Ricordi islet isolation method. Transplantation. 2006;82(4): $460-465$.

27. Gray DWR, Mc Shane P, Grant A, et al. A method for isolation of islet of Langerhans from the human pancreas. Diabetes. 1984;33:1055-1061.

28. Rajotte RV. Islet cryopreservation protocols. Ann N Y Acad Sci. 1999;875:200-207.
29. Gatto C, Callegari M, Folin M, et al. Effects of cryopreservation and coculture with pancreatic ductal epithelial cells on insulin secretion from human pancreatic islets. Int $\mathrm{J} \mathrm{Mol} \mathrm{Med}$. 2003;12(6):851-854.

30. Piemonti L, Bertuzzi F, Nano R. et al. Effects of cryopreservation on in vitro and in vivo long-term function of human islets. Transplantation. 1999;68(5):655-662.

31. Freshney R. Culture of Animal Cells: A Manual of Basic Technique. New York, NY: Alan R Liss Inc; 1987.

32. Papas KK, Hering BJ, Guenther L, et al. Pancreas oxygenation is limited during preservation with the two-layer method. Transplant Proc. 2005;37(8):3501-3504.

33. Agrawal A, So PW, Penman A, et al. Limited penetration of perfluorocarbon in porcine pancreas preserved by two-layer method with 19fluorine magnetic resonance spectroscopy and headspace gas chromatography. Cell Transplant. 2010;19(8):10211029.

34. Bouwens L. Islet morphogenesis and stem cell markers. Cell Biochem Biophys. 2004;40(3 Suppl):81-88. 